\title{
EFFECT OF DIFFERENT COMBINATIONS OF FEED MATERIALS ON GROWTH AND DEVELOPMENT OF EARTHWORM EUTYPHOEUS WALTONI
}

\author{
Keshav Singh* \\ *Vermibiotechnology Laboratory, \\ Department of Zoology, D.D.U. Gorakhpur University, Gorakhpur-273 001, U.P. India. \\ Email: keshav26singh@ rediffmail.com \\ Mob: 9450433313
}

\begin{abstract}
The effect of various animal agro and kitchen wastes on the growth and development of an earthworm Eutyphoeus waltoni was studied under identical laboratory condition. There was observed significant growth and development of earthworm among combination of buffalo dung with agro and kitchen wastes. Maximum number of earthworm was observed in buffalo dung with gram bran. Highest significant growth was observed in gram bran with cattle dung. Whereas, the maximum significant gain in weight and length attained in combination of gram bran with buffalo dung. Therefore, buffalo dung in combination with gram bran was very potent to be used for growth and development of earthworm Eutyphoeus waltoni when it combined with gram bran.
\end{abstract}

KEYWORDS: Animal dung, Development, Eutyphoeus waltoni, Growth, Wastes.

\section{INTRODUCTION}

Excessive use of chemical fertilizers makes the soil infertile and reduces productivity. Generation of organic agrowastes has increased at an unprecedented rate around the globe, because of increased food grain production to feed the population, leading to disposal problems 9 . India produces around 3000 MT (million tonnes) of organic waste annually ${ }^{2}$ and according to conservative estimates, around 600-700 MT of agricultural wastes (including $272 \mathrm{MT}$ of crop residues) is available in India every year, but most of it is unutilized ${ }^{\mathbf{1 , 2 1}}$ for sustainable practices. In India the livestock dung are produced annually millions of tons as the rate of buffalo dung $12.20 \mathrm{~kg}$ animal $^{-1}$ day $^{-1}$, cow dung $11.6 \mathrm{~kg}$ animal $^{-1}$ day $^{-1}$ and goat dung $0.70 \mathrm{~kg}$ animal $^{-1}$ day $^{-1}{ }^{7}$. Earthworms are one of the major soil macro invertebrates and are known for their contributions to soil formation and turnover with their widespread global distribution ${ }^{15}$. Vermicomposting is one of the most important tools in the campaign to recycle agricultural wastes as biofertilizers ${ }^{18}$. The US geological survey found that the increase in in-stream loads of nitrogen and phosphorus was strongly correlated with increased animal concentrations. Organic wastes can be ingested by earthworms and egested as a peat-like material termed as vermicompost.

Different combinations of cattle dung (sheep, horse, goat, buffalo) with agrowastes (vegetable waste, wheat bran, rice bran, gram bran, barley bran, straw) have been used as an effective tool for vermicomposting ${ }^{\mathbf{1 8}}$. Addition of vermicompost enhances the soil fertility as 
changes physical and chemical properties of soil ${ }^{16}$. The growth and reproduction of the earthworm are significantly affected by various factors such as waste type, temperature, density, moisture, chemical complexity, bulky material, and earthworm species during vermicomposting ${ }^{22}$. As huge amount of wastes can be managed through more population of earthworms ${ }^{8}$ reproductive and growth performance of various species of earthworms in a range of substrates can act as useful biomarkers to measure the efficiency of an earthworm species in vermicomposting or earthworm based biotechnology ${ }^{20}$. Eutyphoeus waltoni is an anecic earthworm species that is widespread in India ${ }^{17}$. Eutyphoeus waltoni has been found abundantly in the agricultural fields of eastern U.P. and the sufficient number of Eutyphoeus waltoni is necessary for better recycling of wastes in agricultural fields ${ }^{10}$. The biomass gain and cocoon production by Eisenia fetida was more in cattle waste than goat waste ${ }^{\mathbf{1 1}}$. Earthworm seems to be a potential tool to overcome or reduce both feed cost and waste disposal challenges by conversion of negative wastes into beneficial materials.

The aim of present work was to access the growth and development of Eutyphoeus waltoni in different combination of animal, agro and kitchen wastes.

\section{MATERIALS AND METHODS}

\section{Collection and Culturing of the Earthworm:}

Adult earthworm Eutyphoeus waltoni, were randomly picked from several stock culture maintained in the vermiculture research center, Department of Zoology, D. D.U. Gorakhpur University, Gorakhpur, U.P.

\section{Collection of Cattle Wastes:}

The fresh wastes of animal viz. buffalo were collected from animal farms located in Gorakhpur city. The animal dung was used after 10 days of collection because pre-composting is very essential to avoid the death of the worms.

\section{Collection of Agro and Kitchen Waste:}

The organic wastes (agro and kitchen) used as substrate were collected from the garbage and different parts of villages, situated under the Gorakhpur region. All the samples were kept at normal room temperature for biological and visual analysis.

\section{Experimental Design:}

Measurement of growth (length, weight and number) of Eutyphoeus waltoni was conducted on cemented surface of the floor. $2 \mathrm{~kg}$ of combination (ratio 1:1) was put on $30 \mathrm{~cm} \times 30 \mathrm{~cm} \times 10 \mathrm{~cm}$ areas at cool and elevated places on the floor. Animal dung measured as control. The combinations turn over manually every $\mathrm{n} 24 \mathrm{hr}$ for 10 days in order to eliminate the volatile substances. The moisture content was maintained during experimental period between 40-60 percent. After 60 days the total number of earthworm and their length and weight were counted from each bed. Each experiment was replicated at 6 times. 
Statistical Analysis:

Data have been expressed as mean \pm SE of 6 replicates. Student's t-test was applied to compare the significant $(\mathrm{P}<0.05)$ between different cattle dung and different combination of cattle dung with agro and kitchen wastes ${ }^{19}$.

\section{RESULTS AND DISCUSSION}

Table: Effect of animal dung and its combinations with agro / kitchen waste on the growth and development of earthworm Eutyphoeus waltoni

\begin{tabular}{|l|c|c|c|}
\hline Wastes & Number & Weight & Length \\
\hline Buffalo Dung & $67.00 \pm 0.89$ & $748.02 \pm 32.43$ & $6.28 \pm 0.7$ \\
Dung +Gram Bran & $107.00 \pm 0.77 *$ & $1132.45 \pm 33.03 *$ & $9.68 \pm 0.21 *$ \\
Dung + Straw & $99.76 \pm 0.81 *$ & $963.31 \pm 38.40 *$ & $8.92 \pm 0.61$ \\
Dung + Wheat Bran & $91.94 \pm 0.75 *$ & $924.51 \pm 38.52 *$ & $8.12 \pm 0.23$ \\
Dung + Rice Bran & $82.01 \pm 0.62 *$ & $783.80 \pm 27.00 *$ & $7.50 \pm 0.02$ \\
Dung+ Vegetable Wastes & $68.02 \pm 0.02$ & $729.90 \pm 36.99$ & $7.92 \pm 0.23$ \\
Dung + Barley Bran & $106.98 \pm 0.59 *$ & $1048.38 \pm 31.06^{*}$ & $9.12 \pm 0.32$ \\
\hline
\end{tabular}

Each value is mean \pm SD of 6 replicates.

*Significant $(\mathrm{P}<0.05, \mathrm{t}$ test $)$ between treated and control group.

Number counted in $30.0 \times 30.0 \times 10.0 \mathrm{~cm}$ area of vermicomposting bed.

The combination of cattle dung, agro and kitchen wastes caused a significant growth in the Eutyphoeus waltoni. There was significant increase in number, weight and length of earthworm in combination of buffalo dung with agro/kitchen wastes with respect to cattle dung only. The average weight gain $1132.45 \mathrm{mg} /$ animal and length $9.68 \mathrm{~cm} /$ animal were observed in the Eutyphoeus waltoni inoculated in bed of buffalo dung with gram bran. Highest increase in number of earthworm after 60 days of inoculation was observed in bed of buffalo dung + gram bran (107) with respect to 20 inoculated earthworms in the beginning. However, the number of earthworms in buffalo dung was observed to be $67.00 \pm 0.89$. Two ways ANOVA applied in between the different combination of buffalo dung and agro/ kitchen wastes demonstrated that there is a significant variation in between number and weight of the column of different combination.

The different binary combination of buffalo dung with agro-wastes rice bran, wheat straw, barley bran, gram bran and banana peels caused a significant growth of E. fetida as well as significantly increase in number of cocoons, clitellum development and initiation of cocoon production and 
weight gain $^{18}$. So for our experiment we have taken buffalo dung with combination of agro and kitchen wastes to examine the growth and development of earthworm Eutyphoeus waltoni because buffalo dung was very potent to be used. The physical and chemical parameters were changed in all final vermicomposts with respect to initial feed mixtures. The agro wastes have low nitrogen residue due to immobilization of inorganic nitrogen of soil by microbes resulted unavailable to plants ${ }^{3}$. Throughout the world, earthworms play an important role in determining the balance of greenhouse gases from soils, and their impact is expected to increase in the coming decades ${ }^{12}$. The different variables necessary for earthworm production, the type of food seems to be most important ${ }^{6}$. Worms could not survive in fresh cattle solids, pig solids, fruit wastes, or vegetable wastes. The reproduction pattern of earthworms was different among different combinations, depending on the quality of the worm feed. The rate of weight gain by E. fetida is dependent on population density and the type of food $^{\mathbf{1 4}}$. Indeed, $1 \mathrm{~kg}$ of adults earthworm can convert up to $5 \mathrm{~kg}$ of waste per day and approximately $10 \mathrm{~kg}$ of adults can convert one ton waste per month. Growth rate is a good indicator for comparing the growth of earthworms in different wastes. ${ }^{5}$. The feed material of buffalo dung with gram bran have rich organic nutrients ${ }^{\mathbf{1 3}}$. Feeds that provides earthworms with sufficient amount of easily metabolizable organic matter and nonassimilated carbohydrate, favor growth and reproduction of earthworms ${ }^{4}$. Therefore, we got significant result due to combination of agro and kitchen wastes with animal dungs. The average weight gain $1132.45 \pm 33.03 \mathrm{mg} /$ animal and length $9.68 \mathrm{~cm} /$ animal were observed in the inoculated bed of buffalo with gram bran. The maximum increase and decomposition in the number of earthworms in combination of buffalo with gram bran is due to the biochemical quality of food, which is an important factor in determining the time taken to reach sexual maturity and onset reproduction.

The observation, indicate that the combination of agro and kitchen wastes, with buffalo dung shows significant growth and development of Eutyphoeus waltoni. The combination of agro and kitchen wastes with buffalo dung provides an environment for better growth and development of Eutyphoeus waltoni. The growth and reproduction of Eutyphoeus waltoni were highest when allowed to feed on buffalo dung with gram bran. Thus, the combination of gram bran with buffalo dung is suitable for better growth and development of earthworm Eutyphoeus waltoni.

\section{REFERENCES}

1. Alok, A., A.K. Tripathi and P. Soni, 2008. Vermicomposting: A Better option for organic solid waste management. J. Hum. Ecol., 24(1): 59-64.

2. Bharadwaj, A., 2010. Management of kitchen waste material through vermicomposting. Asian. J. Exp. Biol. Sci., 1(1): 175-77.

3. Brady, N.C. and R.R. Weil, 2002. The nature and properties of soils, 13th ed. Pearson Education Singapur, pp. 960. 
4. Edwards, C.A., 1988. Breakdown of animal, vegetable and industrial organic wastes by earthworms. The Hague. pp: 21-31. In: Edwards, C.A., Neuhauser, E.F. Eds, (Earthworms in wastes and Environmental Management. SPB Academic Publishing).

5. Edwards, C.A., J. Dominguez and E.F Neuhauser, 1998. Growth and reproduction of Perionyx excavatus (Per.) (Megascolecidae) as factors in organic waste management. Biology and Fertility of Soils 27: 155-161.

6. Fayolle, L., H. Mitchell, D. Cluzeau and J. Stawiec, 1997. Influnence of temperature and food source on the life cycle of the earthworm Dendrobaena veneta (Oligochaeta). Soil Biology and Biochemistry, 29: 747-750.

7. Garg, P., A. Gupta and S. Satya, 2006. Vermicomposting of different types of waste using Eisenia foetida: A comparative study. Biores Technol., 97: 391-395.

8. Garg, V.K. and P. Kaushik, 2005. Vermistabilization of textile mill sludge spiked with poultry droppings by an epigeic earthworm Eisenia fetida. Biores. Technol., 96:1063-1071.

9. Grewal, A., S.S. Hundal and S. Sharma, 2016. Bio management of agro-origin wastes for value addition. J. Environ. Res. Develop., 10(4): 700-705.

10. Kumar, Y. and K. Singh, 2013. Distribution of Earthworm in Different Block of Gorakhpur District in Eastern Uttar Pradesh. World. Appl. Sci. J., 21(9): 1379-1385. DOI: 10.5829/idosi.wasj.2013.21.9.936.

11. Loh, T.C., Y.C. Lee, J.B. Liang and D. Tan, 2004. Vermicomposting of cattle and goat manures by Eisenia foetida and their growth and reproduction performance. - Biores. Technol., 96: 11-114.

12. Lubbers, I.M., K.J.V. Groenigen, S.J. Fonte, J. Six, L. Brussaard, J.W.V. Groenigen, 2013. Greenhouse-gas emissions from soils increased by earthworms. Nature Climate Change 3:187-194.
13. Nath, G., K. Singh and D.K. Singh, 2009. Effect of different combinations of animal dung and agro/ kitchen wastes on growth and development of earthworm Eisenia foetida. Australian. J. Basic. App. Sci., 3: 3553-3556.

14. Neuhauser, E.F., R. Hartenstein and D.L. Kaplan, 1980. Growth of the earthworm Eisenia foetida in relation to population density and food rationing. OIKOS 35: 93-98.

15. Norbu, T., 2002. Pretreatment of municipal solid waste by windrow composting and vermicomposting.

16. Purakeyastha, T.J. and R.K. Bhatnagar, 1997. Vermicompost: a promising source of plants nutrients. India Fmg., 46(2): 35-37.

17. Singh, J., A. Singh and A.P. Vig, 2015. Occurrence of Metaphire houlleti (Perrier, 1872) and Eutyphoeus waltoni (Michaelson, 1907) (Annelida: Oligochaeta) from Amritsar, India. U.P. J. Zool. 35(3):201-206.

18. Singh, K., G. Nath, R. Rai and R.C. Shukla, 2013. Food preference of Eisenia foetida among different combinations of animal dung and agro/kitchen Wastes. Bot. Resear. Int., 6(1): 23-26.

19. Sokal, R.R. and F.J. Rohlf, 1973. Introduction of biostatistics. W. H. Freeman \& Co.San Francisco.

20. Suthar, S., 2007. Influence of different food sources on growth and reproduction performance of composting Epigeics: Eudrilus Eugeniae, Perionyx Excavatus and Perionyx Sansibaricus. App. Ecol. Env. Res., 5(2):79-92.

21. Suthar, S., 2009. Nutrient changes and bio dynamics of epigeic earthworm, Perionyx excavatus (Perrier) during recycling of some agricultural wastes. Bio resource. Tech., doi.10 1016/j. biotech.

22. Yadav, A. and V.K. Garg, 2010. Bioconversion of food industry sludge into value-added product (vermicompost) using epigeic earthworm Eisenia fetida. World Revi. Sci. Technol. Sust. Dev., 7(3):225-238. 